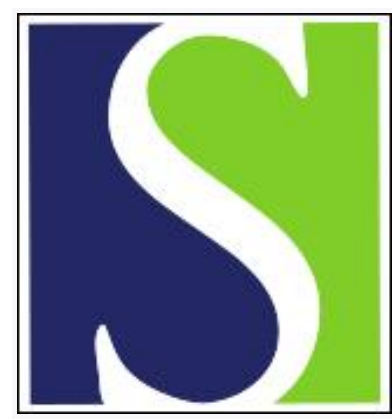

Scand J Work Environ Health 2010;36(6):458-465

https://doi.org/10.5271/sjweh.2985

Published online: 23 Apr 2010, Issue date: Nov 2010

The impact of junior doctors' worktime arrangements on their fatigue and well-being

by Tucker P, Brown M, Dahlgren A, Davies G, Ebden P, Folkard S, Hutchings $\mathrm{H}$, Ákerstedt $\mathrm{T}$

Affiliation: Department of Psychology, Swansea University, Swansea SA2 8PP, United Kingdom. p.t.tucker@swan.ac.uk

Refers to the following texts of the Journal: 2008;34(5):356-363

2009;35(5):361-367

The following articles refer to this text: 2011;37(3):169-171;

2019;45(2):166-173

Key terms: doctor; European Working Time Directive; fatigue; health; junior doctor; medical worker; physician; risk; shift work; sleep; well-being; work-life interference; working time; worktime; worktime arrangement

This article in PubMed: www.ncbi.nlm.nih.gov/pubmed/20414629 


\title{
The impact of junior doctors' worktime arrangements on their fatigue and well-being
}

\author{
by Philip Tucker, PhD, ${ }^{1}$ Menna Brown, MSc, ${ }^{2}$ Anna Dahlgren, PhD, ${ }^{3}$ Gwyneth Davies, MD, 2, 4 Philip Ebden, \\ $M D,{ }^{2,4}$ Simon Folkard, DSc, ${ }^{1,5}$ Hayley Hutchings, PhD, ${ }^{2}$ Torbjörn Åkerstedt, PhD ${ }^{6}$
}

\begin{abstract}
Tucker P, Brown M, Dahlgren A, Davies G, Ebden P, Folkard S, Hutchings H, Åkerstedt T. The impact of junior doctors' worktime arrangements on their fatigue and well-being. Scand J Work Environ Health. 2010;36(6):458-465.

Objective Many doctors report working excessively demanding schedules that comply with the European Working Time Directive (EWTD). We compared groups of junior doctors working on different schedules in order to identify which features of schedule design most negatively affected their fatigue and well-being in recent weeks.
\end{abstract}

Methods Completed by 336 doctors, the questionnaires focused on the respondents' personal circumstances, work situation, work schedules, sleep, and perceptions of fatigue, work-life balance and psychological strain.

\begin{abstract}
Results Working 7 consecutive nights was associated with greater accumulated fatigue and greater work-life interference, compared with working just 3 or 4 nights. Having only 1 rest day after working nights was associated with increased fatigue. Working a weekend on-call between 2 consecutive working weeks was associated with increased work-life interference. Working frequent on-calls (either on weekends or during the week) was associated with increased work-life interference and psychological strain. Inter-shift intervals of $<10$ hours were associated with shorter periods of sleep and increased fatigue. The number of hours worked per week was positively associated with work-life interference and fatigue on night shifts.
\end{abstract}

Conclusion The current findings identify parameters, in addition to those specified in the EWTD, for designing schedules that limit their impact on doctors' fatigue and well-being.

Key terms European Working Time Directive; health; medical worker; physician; risk; shift work; sleep; work-life interference.

The phased implementation of the European Working Time Directive (EWTD) (1) in junior doctors' worktime arrangements has brought about a radical reorganization of the way trainee doctors work in the UK. The implementation of the Directive took place between 2004-2009. Prior to 2004, doctors were able to work very long duty periods, including periods of on-call working running contiguously with normal duty hours (up to 56 hours of continuous duty at weekends). However, the European Court of Justice judged this "residency on-call" practice to be in contravention of the EWTD and ruled that being asleep while on-call counts as working because the doctor is required to be on-site $(2,3)$. This was a key factor leading to the introduction of rotating shift systems that have now largely replaced the traditional arrangements. One of the key aims of the new worktime arrangements was to reduce excessive fatigue among junior doctors, thereby enhancing patient safety and doctors' own well-being. However, the implementation of the EWTD has not led to an improvement in the situation in all cases, with highly demanding, yet EWTD-compliant work schedules commonly reported by junior doctors (4).

Shift work, and night working in particular, impacts sleep, family, social life, mood, vigilance, job performance, and mental and physical health (5-8). The

1 Department of Psychology, Swansea University, Swansea, United Kingdom.

2 School of Medicine, Swansea University, Swansea, United Kingdom.

3 Department of Shipping and Marine Technology, Chalmers University, Gothenburg, Sweden.

4 Singleton Hospital, Swansea, United Kingdom.

5 Laboratory of Applied Anthropology, Paris Descartes University, Paris, France.

6 Stress Research Institute, Stockholm University, Stockholm, Sweden.

Correspondence to: Dr Philip Tucker, Department of Psychology, Swansea University, Swansea SA2 8PP, United Kingdom. [E-mail: p.t.tucker@swan.ac.uk] 
design of shift rotas (eg, the particular sequences of shifts worked, the lengths of individual shifts) moderates the impact of shift working on the individual (9). Several studies have identified the impact of doctors' work schedules on their cognitive performance (10), susceptibility to making medical errors $(11,12)$, and their well-being $(13,14)$. However, no studies have examined the relative impact of the broad range of shift systems that have been introduced in the wake of the implementation of the EWTD.

The aim of our study was to examine the impact of various schedule features by studying groups of doctors working on different rotas. We sought to determine the impact of particular aspects of shift system design on four dependent variables: fatigue, sleep duration, psychological strain, and work-life interference. The schedule features to be examined were identified from a series of interviews and focus groups involving junior doctors and hospital managers [reported elsewhere (4)] and from a review of the relevant literature on shift work. The schedule features identified for examination were: (i) the number of night shifts worked consecutively, (ii) the length of night shifts, (iii) the number of scheduled rest days following a block of night shifts, (iv) the number of consecutive shifts (of any sort) worked without a break, (v) the frequency of weekends on-call, (vi) the frequency of daytime on-call shifts (Monday to Friday), (vii) the length of daytime on-call shifts, (viii) shorter intervals between the end of one shift and the start of the next ("quick returns"), (ix) and the number of hours worked per week.

\section{Methods}

\section{Ethics}

Ethical approval for the conduct of the survey was obtained from the Multi-Centre Research Ethics Committee for Wales (Ref: 07/MRE09/18).

\section{Sample}

Two questionnaire surveys were conducted six months apart, in December 2007 and June 2008. (The second survey served to improve the response rate obtained in the first.) The target population comprised all junior doctors working in specialties undertaking acute medicine throughout Wales. Questionnaires and pre-paid return envelopes were distributed by post to the target population. Additionally, participants in the second survey were given the option to complete the questionnaire online. A total of 363 questionnaires were received, after excluding respondents who did not work a shift system or undertake out-of-hours work. A further 27 responses to the first survey were excluded as they had come from individuals who had also responded to the second survey. Thus the final sample size for the analyses was 336 out of 725 individuals who were sent a questionnaire in either the first or the second survey (ie, $46 \%$ ).

\section{Work schedules}

When working normal day shifts, junior doctors usually work between 09:00-17:00 hours, Monday to Friday. Night shifts usually start between 21:00-22:00 hours and are worked once every 4-6 weeks, if working 3 or 4 consecutive nights, or once every $8-12$ weeks if working 7 consecutive nights. On-call shifts are used to cover the hours between the end of the normal day shift and the start of the night shift and also to provide weekend cover.

\section{Materials}

The questionnaire was partly based on items taken from the standard shift work index (9) and comprised four sections. The first section covered personal details (ie, gender, age, marital status, number of dependants, use of hospital accommodation, job grade, time since qualification, hospital location, whether studying for exams). Two additional items asked respondents to rate themselves in terms "being a morning person" and "being able to sleep easily at unusual times or in unusual places" (9-point scales; $1=$ definitely not, $9=$ definitely yes).

The second section ascertained details of the respondent's recent shift schedule (ie, weekly work hours, length of day shifts when on-call, number of inter-shift intervals of $<10$ hours in the last 7 days, number of nights off before starting night shifts, length of rest following the end of night shifts, length of a single night shift, number of days worked consecutively before last day off, number of consecutive night shifts, frequency of daytime on-call shifts, frequency of weekends oncall). Four additional items asked respondents to rate their schedule in terms of possibilities for swapping shifts, control over start and finish times (5-point scale; $1=$ none, $5=$ complete), predictability of shifts $(5$-point scale; $1=$ highly predictable, $5=$ =highly unpredictable), and regularity of shift pattern (5-point scale; 1=highly regular repeating pattern, $5=$ does not repeat in any regular manner). Averages of the first two items were calculated (as an estimate of internal consistency, the correlation between the two items was $\mathrm{rho}=0.14, \mathrm{P}<0.01$ ) and the second two items ( $r h o=0.61, \mathrm{P}<0.01)$ to give two overall scores, namely "control over work hours" and "predictability and regularity of schedule".

In the third section, respondents were asked to indicate how long they had slept between different types 
of shifts in recent weeks (ie, normal day shifts, on-call day shifts, the $1^{\text {st }}$ and $3^{\text {rd }}$ shift in a block of nights, and, if appropriate, the $5^{\text {th }}$ and $7^{\text {th }}$ shifts in a block of nights). These ratings represented the dependent variable "sleep duration". For each type of shift, they were also asked to rate their on-shift alertness (9-point scale; $1=$ =ery alert, $9=$ very sleepy, fighting sleep), susceptibility to making minor errors (9-point scale; $1=$ very unlikely, $9=$ very likely), and confidence in their ability to drive home safely (9-point scale; $1=$ very confident, 9=very unconfident). Scores on these three items were averaged to give an overall score of fatigue for each type of shift. These ratings represented the dependent variable "fatigue". (For each shift, internal consistency measures were calculated for the three items, giving Cronbach's $\alpha$ ranging between $0.49-0.90$ ).

In the fourth section, respondents were asked to rate their perceived workload on a normal day, on-call, and during night shifts (9-point scale; 1=extremely light, $9=$ extremely heavy). They were also asked to rate how much their work schedule interfered with their social and home life, personal relationships, and other commitments (9-point scale, $1=$ not at all, $9=$ very much). Scores on these four items were averaged (Cronbach's $\alpha=0.91$ ) to give an overall work-life interference score. These ratings represented the dependent variable "work-life interference". Respondents were also asked to complete a measure of psychological strain: the General Health Questionnaire (15). The 12 items variously referred to the respondent's emotional state and coping ability experienced over the past few weeks. Individual item scores were summed (Cronbach's $\alpha=0.86$ ), giving possible total scores ranging from 0 (very low strain) to 36 (very high strain). These ratings represented the dependent variable "psychological strain". [For comparison purposes, scores for a sample of employees in an engineering plant were: males, mean $=8.80$ (standard error [SE] 0.17); females, mean=8.53, (SE 0.40) (16).]

\section{Data analysis}

Analyses were conducted using a combination of univariate and repeated measures, analysis of variance and co-variance [ANOVA/ANCOVA (employing the Bonferroni correction for multiple post hoc comparisons where appropriate)], as well as multiple regressions where appropriate. The analyses that compared between groups controlled for a range of individual and circumstantial differences. These were the variables from the first section of the questionnaire listed above, plus patient load (ie, the patient-to-doctor ratio), first or second survey, perceived workload, control over work hours, and predictability and regularity of schedule. The variables to be used in the analyses were screened for outliers and distributional assumptions were checked (17). For the sake of parsimony, the description of the results that follow focuses only on significant (and marginally nonsignificant) effects of shift system features $(\mathrm{P}<0.05)$.

\section{Results}

The average age of respondents was 28.7 years [standard deviation (SD) 4.8]. Of the entire sample, $50 \%$ were female, $59.5 \%$ were married/living with partner, $39 \%$ were single and $0.6 \%$ were separated/widowed. Three quarters reported having no dependants (eg, children) living with them. A series of analyses were conducted to determine whether the distributions within the sample differed from the distributions within the target population. The sample was compared to the target population in terms of the distributions of (i) gender; (ii) medical sub-specialties in which respondents worked; (iii) location (ie, hospital); and (iv) training grade. The first three analyses indicated that the distributions were representative of the target population. The fourth analysis indicated that senior grades (specialist registrars) were somewhat under-represented and so data in the analyses that follow were weighted accordingly.

\section{Number of consecutive night shifts}

When working night shifts, the majority of respondents worked either 7 consecutive shifts $(\mathrm{N}=118)$, or they alternated between working 3 and 4 consecutive shifts in a block of nights $(\mathrm{N}=136)$. Figure 1 illustrates the length of sleep obtained before day and night shifts. In the first analysis, a single-factor repeated measures ANOVA compared sleep durations for the $3^{\text {rd }}, 5^{\text {th }}$ and $7^{\text {th }}$ night (ie, sleep taken during the day before the night shift), in the group that worked 7 consecutive night shifts. There was a significant increase over the 3 periods of sleep $(F=6.22$, $\mathrm{P}=0.002$ ). A second comparison indicated that the last of these sleep periods (ie, the sleep taken before the $7^{\text {th }}$ night shift) was significantly shorter than the night sleep taken when working day shifts $(\mathrm{F}=43.39, \mathrm{P}<0.001)$.

Figure 2 illustrates the levels of fatigue associated with day and night shifts. Median values of risk scores were: day $=2.3,1^{\text {st }}$ night $=4.8,3^{\text {rd }}$ night $=5.0,5^{\text {th }}$ night $=6.0$, $7^{\text {th }}$ night $=6.7$. In comparison, a survey of aircraft maintenance workers using the same measure obtained median values of: day shift=3.0, night shift=4.8 (18).

A two-factor repeated measures ANCOVA, comparing fatigue scores in the two groups on their $1^{\text {st }}$ and $3^{\text {rd }}$ night shifts, indicated that there were no significant main effects, nor was there a significant interaction. That is to say, there was no increase in fatigue from the $1^{\text {st }}$ to the $3^{\text {rd }}$ night shift in either group. A second analysis comparing the two groups on their $1^{\text {st }}$ and last 

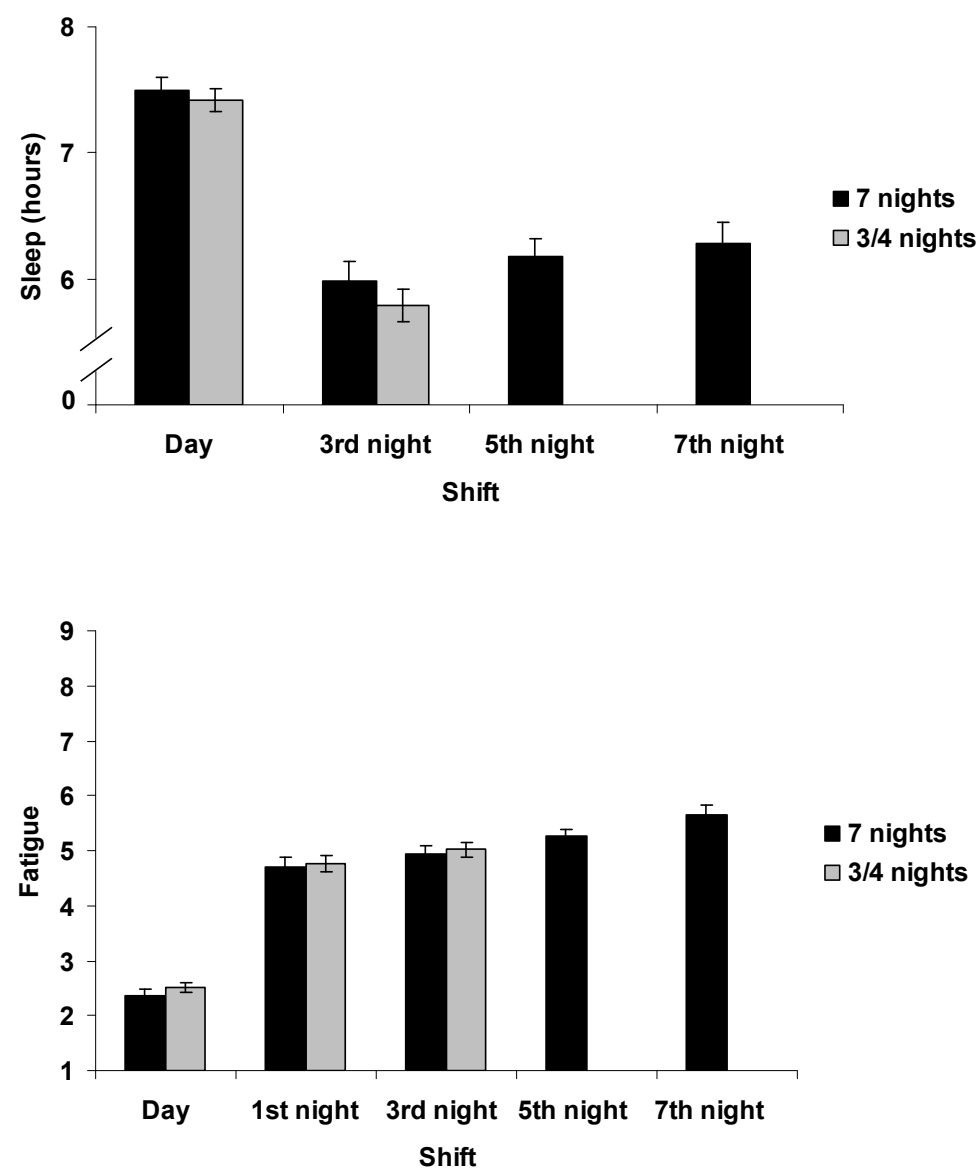

Figure 1. Duration of main sleep before shift (mean and standard error) reported by those working 3 or 4 consecutive night shifts and those working 7 consecutive nights.

Figure 2. Fatigue associated with each shift (mean and standard error) reported by those working 3 or 4 consecutive night shifts and those working 7 consecutive nights.

night shifts (or last but 1 in the case of those working 4 nights) indicated that there were no significant main effects, but that the interaction term was significant $(\mathrm{F}=12.55, \mathrm{P}<0.001)$. Post hoc simple main effects analyses indicated that the two groups only differed significantly on their last night shift (ie, their $3^{\text {rd }}$ and $7^{\text {th }}$ night shift, respectively; $\left.\mathrm{F}=4.54, \mathrm{P}=0.034\right)$.

A univariate ANCOVA indicated that work-life interference was lower among those who worked 3 or 4 nights at a time than among those working 7 consecutive nights $[3$ or 4 nights mean $=5.65$ (SE 0.13); 7 nights mean=6.09 (SE 0.14); $\mathrm{F}=4.60, \mathrm{P}=0.033]$.

\section{Number of rest days following a block of nights}

Some of those working 3 or 4 consecutive nights reported getting only 1 rest day following their block of nights, while others got $\geq 2$ rest days after their night shifts. Of those working 7 consecutive nights, virtually all got $\geq 2$ rest days after their night shifts. A univariate ANCOVA indicated that respondents in the first group ( 3 or 4 nights followed by only 1 day rest) reported greater fatigue on their $1^{\text {st }}$ day shift following a block of nights $[\mathrm{N}=100$, mean $=4.62(\mathrm{SE} \mathrm{0.17)}]$, compared to the other groups [3 or 4 nights followed by $>1$ day rest: $\mathrm{N}=29$, mean $=3.29(\mathrm{SE} 0.32)$; 7 nights followed by $>1$ day rest: $\mathrm{N}=85$, mean=3.39 (SE 0.19); $\mathrm{F}=13.43, \mathrm{P}<0.001]$.

\section{Number of consecutive shifts without a break}

The majority of respondents reported having worked either 5 days prior to their last break or 11-12 days. The latter group are assumed to have worked a weekend oncall between 2 successive working weeks. A univariate ANCOVA indicated that this group reported more worklife interference and somewhat greater psychological strain, although the latter difference was marginally non-significant (see table 1).

\section{Frequency of weekends on-call}

Regression analysis indicated that more frequent weekend working [mean=1 weekend every 5.82 weeks (SE $0.16)]$ disrupted life outside work [mean $=5.86$ (SE $\left.0.17) ; \beta=-0.15, \Delta \mathrm{R}^{2}=0.02, \mathrm{P}=0.007\right]$ and was associated with higher psychological strain [mean=12.45 (SE 0.29); $\left.\beta=-0.12, \Delta \mathrm{R}^{2}=0.01, \mathrm{P}=0.039\right]$. 


\section{Frequency of daytime on-call shifts (Monday-Friday)}

Regression analysis indicated an association between the frequency of weekdays on-calls [mean $=1$ on-call every 8.76 days (SE 0.44)] and work-life interference [mean=5.81 (SE 0.10); $\beta=-0.16, \Delta \mathrm{R}^{2}=0.02, \mathrm{P}=0.005$ ], as well as between frequency and psychological strain [mean=12.43 (SE 0.30); $\beta=-0.15, \Delta \mathrm{R}^{2}=0.02, \mathrm{P}=0.013$ ]. Additional analysis indicated that the greatest differences were between those who worked $>1$ on-call per week and those working $\leq 1$ per week (see table 1 ).

\section{Quick returns}

Some respondents reported having had at least 1 quick return (ie, interval of $<10$ hours between the end of one shift and the start of the next) in the last 7 days. A univariate ANCOVA indicated that these respondents reported shorter sleeps following long day shifts (ie, on-call shifts) and greater fatigue on normal day shifts, compared to those who had had no quick returns (see table 2).

\section{Number of hours worked per week}

Univariate ANCOVA, in which respondents were banded into quartiles in terms of their weekly work hours, indicated significant effects of weekly hours on night shift fatigue and work-life interference (see table 3 ). The main differences were apparent between those working $\leq 48$ hours per week and those working more.

\section{Discussion}

The main features of the EWTD for junior doctors are: an average of 48 hours worktime each week, measured over a reference period of 26 weeks; 11 hours continuous rest in 24 hours; 24-hour continuous rest in 7 days (or 48 hours in 14 days); a 20-minute break in work periods of $>6$ hours; 5.6 weeks annual leave; and an average of $\leq 8$ hours of night work in any 24-hour period, over the reference period (19). Important as these requirements are, the current findings highlight a number of additional parameters that need to be considered when seeking to reduce excessive fatigue and safeguard doctors' well-being.

Working 7 consecutive nights resulted in an accumulation of fatigue to levels substantially higher than experienced by those working just 3 or 4 nights in row. This accords with previous research (7) indicating that accident risk increases in an approximately linear fashion across successive night shifts. One of the prime causes of such an accumulation of fatigue is suggested by the
Table 1. Comparision of the number of consecutive shifts worked and the frequency of weekday on-calls.

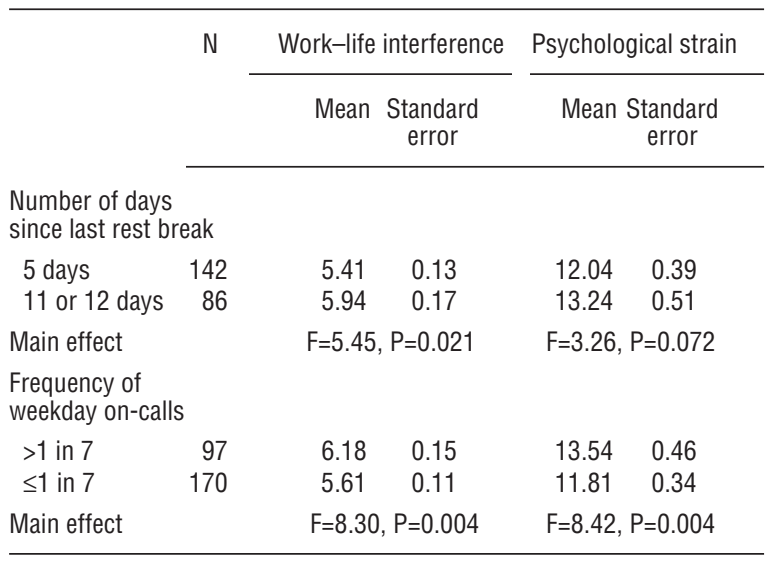

Table 2. Comparison of experience of quick returns.

\begin{tabular}{|c|c|c|c|c|c|}
\hline & \multirow[t]{2}{*}{ N } & \multicolumn{2}{|c|}{$\begin{array}{l}\text { Sleep after } \\
\text { on-call shift }\end{array}$} & \multicolumn{2}{|c|}{$\begin{array}{l}\text { Fatigue on } \\
\text { normal day shift }\end{array}$} \\
\hline & & Mean & $\begin{array}{l}\text { Standard } \\
\text { error }\end{array}$ & Mean & $\begin{array}{l}\text { Standard } \\
\text { error }\end{array}$ \\
\hline \multicolumn{6}{|c|}{$\begin{array}{l}\text { Quick return ( }<10 \text { hours) } \\
\text { in the last } 7 \text { days? }\end{array}$} \\
\hline $\begin{array}{l}\text { No quick returns } \\
\geq 1 \text { quick return }\end{array}$ & $\begin{array}{r}231 \\
60\end{array}$ & $\begin{array}{l}6.87 \\
6.44\end{array}$ & $\begin{array}{l}0.06 \\
0.13\end{array}$ & $\begin{array}{l}2.36 \\
2.70\end{array}$ & $\begin{array}{l}0.07 \\
0.14\end{array}$ \\
\hline Main effect & & \multicolumn{2}{|c|}{$F=8.39, P<0.001$} & \multicolumn{2}{|c|}{$\mathrm{F}=4.67, \mathrm{P}=0.032$} \\
\hline
\end{tabular}

Table 3. Comparison of the length of working weeks.

\begin{tabular}{|c|c|c|c|c|c|}
\hline & \multirow[t]{2}{*}{$\mathrm{N}$} & \multicolumn{2}{|c|}{$\begin{array}{l}\text { Mean night- } \\
\text { shift fatigue }\end{array}$} & \multicolumn{2}{|c|}{$\begin{array}{l}\text { Work-life } \\
\text { interference }\end{array}$} \\
\hline & & Mean & $\begin{array}{l}\text { Standard } \\
\text { error }\end{array}$ & Mean & $\begin{array}{l}\text { Standard } \\
\text { error }\end{array}$ \\
\hline \multicolumn{6}{|c|}{$\begin{array}{l}\text { Hours worked in } \\
\text { last } 7 \text { days }\end{array}$} \\
\hline$<44$ hours & 81 & $\begin{array}{l}4.75 \\
4.59\end{array}$ & 0.20 & 5.37 & 0.17 \\
\hline 45-48 hours & 83 & 4.59 & 0.20 & 5.48 & 0.17 \\
\hline 49-60 hours & 74 & 5.25 & 0.20 & 5.78 & 0.18 \\
\hline$>60$ hours & 72 & 5.29 & 0.20 & 6.13 & 0.18 \\
\hline Main effect & & \multicolumn{2}{|c|}{$F=3.00, P=0.032$} & \multicolumn{2}{|c|}{$F=3.66, P=0.013$} \\
\hline
\end{tabular}

current sleep data. Sleep periods during the day between night shifts were $>1$ hour shorter than night sleep periods between successive day shifts. Some doctors say they prefer working 7 consecutive nights because they find it to be less disruptive of their life outside work. (4) However, this did not appear to be the majority view within the current sample, as working 7 consecutive nights was associated with greater work-life interference. In conclusion, it is prudent to recommend on the grounds 
of patient safety that sequences of no more than 3 or 4 consecutive night shifts be favoured over scheduling 7 night shifts in row, in all but exceptional cases.

Recent evidence from an intervention study reported by Cappuccio et al (12) suggests that further reductions in risk may be achieved by reducing the span of nights even further (ie, to spans of 2 or less often 3 consecutive nights). However, the two-shift systems in that study differed on several important parameters. Thus it is difficult to identify precisely which aspects of the intervention schedule's design significantly contributed to the $33 \%$ reduction in medical errors that was observed. That intervention also involved cutting night shifts from 12.5 to $9-11$ hours. In contrast to the suggestion from that study that the length of night shift contributes to a reduction in risk related to fatigue, the current analyses identified no significant effects of the length of night shifts (or daytime on-call shifts). It is possible that the sensitivity of the current analyses was impaired by the restricted range, with $86 \%$ of the current sample working night shifts of between 12-13 hours in duration.

The length of rest after a block of night shifts affected levels of fatigue experienced on the return to day shifts. Guidelines issued by the UK's Royal College of Physicians suggest that for every 2 nights on duty, $\geq 1$ whole day off should be scheduled (20). The current analysis indicated that 1 day of rest following a block of 3 or 4 nights resulted in the spillover of fatigue effects into the first subsequent day shift. Fatigue on the return to day work was higher among those working a sequence of 3 or 4 days followed by 1 rest day than it was among those that had $\geq 2$ rest days after their block of night shifts. These findings support earlier research indicating that 1 rest day is insufficient for full recovery from night work $(21,22)$.

Working frequent on-call shifts restricts the time available for non-work activities, resulting in increased stress, particularly for those with extra-curricular commitments (eg, families, studying for exams). While a degree of work-life conflict may be inevitable for doctors working on-call, if it is allowed to become too much of a problem it can be harmful to psychological health, with doctors becoming more likely to quit (23). Long on-calls also reduce the time available for sleeping between shifts. The EWTD specifies a minimum break between shifts of 11 hours. However a small number of respondents reported having had $\geq 1$ inter-shift interval of $<10$ hours (a quick return) in the last 2 weeks. (Respondents are unlikely to have been scheduled to work outside the limits specified by the EWTD. Instead, they probably worked for longer than the official duty period, thereby reducing the interval between leaving work and returning for the next shift.) These individuals reported shorter sleep periods after their on-call shifts, suggesting that quick returns are especially likely to occur after an on-call shift. The restricted sleep that results from a short inter-shift interval means that there is a risk of insufficient recovery, resulting in greater fatigue experienced the next day. This was reflected in the increased fatigue ratings associated with quick returns (fatigue on the day following an on-call shift was not measured directly). These findings are concordant with previous research which suggests that quick returns are associated with restricted sleep (24), reduced alertness (25), and increased risk of accidents (26).

Longer weekly hours were associated with both greater fatigue on the night shift and greater work-life interference. It is also notable that those who worked $>48$ hours in the last week experienced markedly more negative effects than those who had worked for $\leq 48$ hours. These findings accord with those of the previously cited intervention study (12) in which doctors working a 48-hour work week demonstrated a substantial reduction in medical errors, compared to doctors on a 56-hour work week.

Our study featured a cross-sectional design and thus care is required when inferring causal relationships from the pattern of results observed. It relied entirely on self-report measures and thus may have been affected by issues of common-method variance $(27,28)$. Furthermore, respondents who like or dislike their shift system for whatever reason (eg, the impact on life outside work) may deliberately or subconsciously distort their responses to other items (eg, ratings of fatigue) accordingly. It was necessary for the purposes of producing a concise questionnaire to use some measures that have not been validated against objective criteria and so caution is needed when extrapolating from such selfreports. The current study deliberately focused exclusively on junior doctors working in specialties undertaking acute medicine. By examining trends within a large relatively homogeneous group rather than a selection of many different specialties, the effects related to work schedule features were less likely to be masked by extraneous variables, such as differences between work routines. However, this means that care should be taken when seeking to generalize to other areas (eg, surgery, accident and emergency). Our study focused exclusively on the impact of work schedules on the individual doctor. It did not seek to examine broader issues that may impact on patient care, such as service cover and staffing levels. Hence the current findings need to be considered alongside the requirements of schemes such as "Hospital at Night" (29). Our study failed to obtain information regarding on-shift napping, meaning that an important determinant of night shift fatigue could not be taken into account. Finally, the number of participants varied between the analyses, meaning that the power to detect differences will have also varied. 
The current findings are based on a higher response than previous surveys $(30,31)$ and provide a more detailed and comprehensive analysis of how shift schedule design features impact on junior doctors. They have highlighted a number of areas of concern in the design of EWTD-compliant shift rotas. When the EWTD was first implemented for junior doctors, some of the newly designed schedules not only failed to eliminate problems of fatigue, but sometimes exacerbated them (32). It was tempting for some to blame the heightened problems on the EWTD itself. However, it could also be argued that the Directive alone was not directly responsible for doctors working excessive night hours. Rather, the situation arose because of the way in which employers responded in their attempts to comply with the EWTD. Although the new work schedules conformed to the Directive's stipulations (eg, a minimum daily rest period of 11 hours), they failed to take into account other parameters that, although not covered by the EWTD, are nevertheless vital considerations in the management of fatigue. The current findings highlight some of these additional parameters, building upon previously published recommendations regarding the design of doctors' working hours and provision of services $(20,33,34)$. One of the unique and crucial contributions of this study is its provision of evidence to support such recommendations, based on junior doctors own experiences of working on EWTD-compliant shift rotas.

\section{Acknowledgements}

This work was supported by the Wales Office of Research \& Development for Health and Social Care, part of the Wales Assembly Government (grant number $\mathrm{ReF06/2/220).}$

\section{References}

1. Council Directive 93/104/EC. Off J Eur Community. 1993;L307:18-24.

2. European Court of Justice. Case C-303/98, Sindicato de Médicos de Asistencia Pública (Simap) and Conselleria de Sanidad y Consumo de la Generalidad Valenciana [Doctors' Union of Public Assistance (Simap) and Counsel of Health of Valencia]. European Court of Justice; 2000.

3. European Court of Justice Case C-151/02, Landeshauptstadt Kiel and Norbert Jaeger [The city of Kiel and Norbert Jaeger]. European Court of Justice; 2003.

4. Brown M, Tucker P, Rapport F, Hutchings H, Dahlgren A, Davies G, et al. The impact of shift patterns on junior doctors' perceptions of fatigue, training, work/life balance and the role of social support. Qual Saf Health Care. In press.

5. Knutsson A. Health disorders of shift workers. Occup Med. 2003;53:103-8.

6. Straif K, Baan R, Grosse Y, Secretan B, Ghissassi F, Bouvard $\mathrm{V}$, et al. Carcinogenicity of shift-work, painting and firefighting. Lancet Oncol. 2007;8(12):1065-6.

7. Folkard S, Tucker P. Shift work, safety and productivity [review]. Occup Med. 2003;53(2):95-101.

8. Bara AC, Arber S. Working shifts and mental health - findings from the British Household Panel Survey (1995-2005). Scand J Work Environ Health. 2009;35(5):361-7.

9. Barton J, Spelten E, Totterdell P, Smith L, Folkard S, Costa G. The standard shiftwork index: a battery of questionnaires for assessing shiftwork-related problems. Work Stress. 1995;9(1):4-30.

10. Arnedt JT, Owens J, Crouch M, Stahl J, Carskadon MA. Neurobehavioral performance of residents after heavy night call vs after alcohol ingestion. JAMA. 2005;294(9):1025-33.

11. Landrigan CP, Rothschild JM, Cronin JW, Kaushal R, Burdick E, Katz JT, et al. Effect of reducing interns' work hours on serious medical errors in intensive care units. N Engl J Med. 2004; 351(18):1838-48.

12. Cappuccio FP, Bakewell A, Taggart FM, Ward G, Ji C, Sullivan $\mathrm{JP}$, et al. Implementing a $48 \mathrm{~h}$ EWTD-compliant rota for junior doctors in the UK does not compromise patients safety: assessor-blind pilot comparison. Q J Med. 2009;102(4):27182.

13. Jagsi R, Surender R. Regulation of junior doctors' work hours: an analysis of British and American doctors' experiences and attitudes. Soc Sci Med. 2004;58(11):2181-91.

14. Smith AM, Morris P, Rowell KO, Clarke S, Jones TH, Channer KS. Junior doctors and the full shift rota - psychological and hormonal changes: a comparative cross-sectional study. Clin Med. 2006;6(2):174-7.

15. Goldberg DP. The detection of psychiatric illness by questionnaire. London: Oxford University Press; 1972.

16. Banks MH, Clegg CW, Jackson PR, Kemp NJ, Stafford EM, Wall TD. The use of the General Health Questionnaire as an indicator of mental health in occupational studies. J Occup Psychol. 1980;53:8.

17. Tabachnick BG, Fidell LS. Using multivariate statistics. $4^{\text {th }}$ edition. Boston (MA): Allyn and Bacon; 2001.

18. Folkard S. Work hours of aircraft maintenance personnel. West Sussex (United Kingdom): Civil Aviation Authority; 2003.

19. Working time directive: frequently asked questions for employer implementation teams. London: National Health Service Confederation; 2009.

20. Horrocks N, Pounder R. Working the night shift: preparation, survival and recovery. London: Royal College of Physicians; 2006.

21. Totterdell P, Spelten E, Smith L, Barton J, Folkard S. Recovery from work shifts: how long does it take? J Appl Psychol. 1995;80(1):43-57. 
22. Åkerstedt T, Kecklund G, Gillberg M, Lowden A, Axelsson J. Sleepiness and days of recovery. Transp Res Part F Traffic Psychol Behav. 2000;3:251-61.

23. Heponiemi T, Kouvonen A, Vanska J, Halila H, Sinervo T, Kivimäki M, et al. Effects of active on-call hours on physicians' turnover intentions and well-being. Scand J Work Environ Health. 2008;34(5):356-63.

24. Axelsson J, Åkerstedt T, Kecklund G, Lowden A. Tolerance to shift work - how does it relate to sleep and wakefullness? Int Arch Occup Environ Health. 2004;77:121-9.

25. Tucker P, Smith L, Macdonald I, Folkard S. Effects of direction of rotation in continuous and discontinuous 8 hour shift systems. Occup Environ Med. 2000; 57:678-84.

26. Macdonald I, Smith L, Lowe SL, Folkard S. Effects on accidents of time into shift and of short breaks between shifts. Int J Occup Environ Health. 1997;3:2:S40-S5.

27. Podsakoff PM, MacKenzie SB, Lee JY, Podsakoff NP. Common method biases in behavioral research: a critical review of the literature and recommended remedies. J Appl Psychol. 2003;88(5):879-903.

28. Salancik GR, Pfeffer J. Examination of need-satisfaction models of job attitudes. Adm Sci Q. 1977; 22(3):427-56.
29. Mahon A, Harris C, Tyrer J, Carr S, Lowson K, Carr L, et al. The implementation and impact of Hospital at Night pilot projects. London: Department of Health; 2005.

30. British Medical Association (BMA). BMA survey of junior doctors' views on working hours and the European Working Time Directive. London: BMA; 2008.

31. Goddard A, Pounder R, McIntyre A, Newbury N. Implementation of the European Working Time Directive in 2009 - implications for UK clinical service provision and training for the medical specialties London: Royal College of Physicians; 2009.

32. Murray A, Pounder R, Mather H, Black DC. Junior doctors' shifts and sleep deprivation [editorial]. Br Med J. 2005;330(7505):1404.

33. Horrocks N, Pounder R. Designing safer rotas for junior doctors in the 48 hour week. London: Royal College of Physicians; 2006.

34. National Health Service (NHS). Hospital at night [Internet]. London: NHS; 2009 [cited 10 June 2009]. Available from: http://www.healthcareworkforce.nhs.uk/hospitalatnight.html

Received for publication: 28 January 2010 